\title{
Making Sense of Social Practice: Theoretical Pluralism in Public Sector Accounting Research: A Reply
}

\author{
KERRY JACOBS*
}

\begin{abstract}
This paper is a reply to Modell's (2013) comment on Jacobs (2012). The aim of the paper is to further explore the issue of theorisation in accounting research. The primary goal of Jacobs (2012) was to map the use of theory in public sector accounting research. Therefore, the danger, as highlighted by Modell (2013), is to read this descriptive analysis as a normative defence. I would echo Modell's concern that authors take care with their 'ontological underpinnings' when blending different theoretical approaches. However, I argue that the more substantive problems are that authors do not establish an accounting 'problem' to motivate their paper, they confuse their case study for their research problem, the theory used is not related to their accounting issue (theorisation) and they theorise the case not their problem. I conclude my response by abandoning my defence for theoretical promiscuity and arguing instead for theoretical serial-monogamy. We should do our best to construct our research arguments to be clear and coherent. However, we should be willing to change our theoretical stance when they do not make sense and show a far higher level of reflexitivity in research design and presentation.
\end{abstract}

Keywords: accounting research, public sector, theory

\section{INTRODUCTION}

The eternal challenge of an academic paper is that you do not have the space to do everything you want to do and choices need to be made about focus and content. I feel that there simply isn't the space to address everything given the scope and scale of public sector accounting research. Therefore, in Jacobs (2012), I chose to map which theoretical perspectives were being used in public

*The author is from the College of Business and Economics, The Australian National University. He would like to acknowledge comments from Habib Mahama and Adam LeBrocq.

Address for correspondence: Kerry Jacobs, Research School of Accounting \& Business Information Systems, College of Business and Economics, The Australian National University, Canberra, Australia.

e-mail: Kerry.Jacobs@anu.edu.au 
sector accounting research and to identify if there were any significant trends in that usage. As recognised by Modell (2013), the three primary conclusions were (1) that there was a considerable body of work that made little direct reference to theory, (2) that there was a diverse set of perspectives in use, dominated by some key approaches such as institutional theory, and (3) that there was a strong tendency to use material from more than one theoretical approach. This was more descriptive than normative and further work is necessary to debate the value and appropriateness of existing theoretical approaches.

\section{A THEORISED RESPONSE}

In Jacobs (2012) I was somewhat 'in the closet' and did not make my theoretical perspective explicit. However, I would defend this decision. The primary objective of the paper was to map the theorisation in public sector accounting research. As such, my aim was to identify what was happening rather than critique what was happening. My choice to start with mapping the current practice is consistent with the methodological approach advocated by Pierre Bourdieu (see Bourdieu and Wacquant, 1992). Presenting a critique without establishing a clear empirical basis is too much like preaching (Bourdieu et al., 1991). Therefore, I would suggest that drawing the theoretically informed conclusions about the relationship between theoretical basis, key authors in the accounting field and the influence of academic journals can reasonably be left to future papers (be they mine or others). I support Modell's (2013) call for further research into the dynamic between entrenched knowledge claims and community of scholars and work to map and explore these dynamics, which should not be dismissed as being 'too subtle and complex'. I suggest that Pierre Bourdieu's ideas exploring the dominant positions in a field and the underlying habitus or dispositions which support and sustain the objective positions could provide a rich and powerful basis to explore the link between the theoretical 'dispositions' of journal editors and key gate-keepers and the kinds of papers published in respective journals.

I broadly welcome and would echo Modell's (2013) challenge to expand the debate about the nature and use of theory in public sector accounting research specifically (and by implication accounting research more generally). Part of the concern that drove Modell may have been triggered by my decision to recognise any significant citation of a theoretical approach as a use of that theoretical approach. In addition, my use of the term 'paradigm' was no more sophisticated than a reference to the major theoretical approaches outlined in the paper. However, I would challenge Modell's (2013) characterisation of my position as 'an unabashed endorsement of theoretical promiscuity [and] as a carte blanche for mindless eclecticism' (Modell 2013, p. 104). I did raise concerns that theoretical approaches were being combined which do not have common epistemological and ontological underpinnings. Only mindful eclecticism should be tolerated. 
The most surprising thing I found in my analysis was how popular it was to combine different theoretical perspectives. Given that Young and Preston (1996) condemned this as 'theoretical promiscuity' and their claim that it was both 'unlikely to happen' and 'if it does it is unlikely to be held in high esteem' (Young and Preston, 1996, p. 110) is simply not true. However, this is not to dismiss Young and Preston's (1996) concerns, which are largely what drives Modell's (2013) comment.

I believe that there are a number of practical problems in how theory is approached in accounting research, and, when these issues are clearly considered, the positions adopted by the different authors can be reconciled. At the heart of the problem are two approaches to theorising accounting research. One approach gives theoretical 'loyalty' primacy. Therefore, the authors will always adopt a given theoretical approach and will 'fit' any empirical material to their theoretical framework. The alternative approach is the trend-driven researcher (which Jacobs, 2012, provides some evidence for) who adopts the current 'popular' theoretical approach to retrospectively theorise their casestudy. In one approach, the case is used to illustrate the theory, and in the other approach, the theory is used to illustrate the case. While both of these approaches can be considered examples of a use of theory, it is questionable whether either of them is particularly useful to research or practice. This criticism is reflected in Vaivio (2008) who challenges qualitative accounting research that has a 'heavy theoretical front-load' but where the theory is not clearly related to the research problem or to the empirical case.

Part of the problem comes from a failure to differentiate between the three different elements to a research argument. In the Craft of Sociology, Bourdieu et al. (1991) argues that there were three different elements in constructing research arguments (1) The break with existing literature, (2) (re)construction of the object of study and (3) confirmation or verification through the mobilisation of evidence. He presents the research project as a process of socially constructed structuralism, as while the socially constructed nature of the research activity is acknowledged, the tastes and preferences of dominant players for certain kinds of arguments and expressions will rapidly 'weed out' those who do not follow the implicit rules of the game (this creating a form of structuralism).

From this perspective, the central problem for many accounting papers is clear: authors confuse their case study with their topic. While areas of the public sector such as health and education are rich and interesting in themselves, they are not accounting topics but case studies. What we need is an accounting topic not a case study. A topic addresses a problem in (or problematises) the accounting literature. A case provides a setting where that problem can be explored. The second mistake is that authors try to theorise the case rather than theorise the research problem. Theorising the case would be presenting a theory of health, education or public sector reform rather than theorising the accounting problem. A third mistake is to confuse the social theory for accounting research. Many authors try to motivate their paper from a particular 
social theory (such as neo-institutional theory, governmentality or actor-network theory) rather than explaining how their theory 'reconstructs' the accounting problem.

A theory gives us what Booth et al. (2008) calls a warrant. In effect a theory allows us to argue why a given case (or any other research approach) would provide evidence to verify our research problem. This is a constructed and argued position, not a 'structural fact'. If a theory is understood as the basis of a research argument, then Humphrey and Scapens' (1996, p. 88) dual claim that 'a theoretical framework is an essential starting point for any case study' and that it [a theory] should be capable of being challenged and refined as part of the research process', makes sense.

Humphrey and Scapens (1996) suggest that case studies need to do more than 'illustrate' particular social theories and that accounting researchers who use these social theories rarely challenge or question their underlying theory. I would argue that the central issue is what we mean by theory and now is the time to engage in an intellectual debate about what really constitutes 'meaningful theory'. Because most of us are accounting researchers rather than sociologists our primary objective is not advancing Foucault, Habermas or Latour but rather to expand our understanding of the nature and functioning of accounting. Our theorisation $^{1}$ is the theorisation of a problem in the accounting literature what Bourdieu called the (re)construction of the object of study. Therefore, the theory and case are both connected as they help us to 'make sense' of our problem.

From this perspective, ontological questions are centrally focused on the nature of the research problem. If the problem is in understanding the micro behaviour of individual actors, then a theory of micro behaviour and sense-making would be most reasonable. However, if we wish to explain the nature and reproduction of institutional structures, then a theory of structural arrangements would seem reasonable. While I recognise that the ontological compatibility of different social theoretical resources, in the sense argued by both Modell (2013) and Young and Preston (1996), this seems to me to be much less of a besetting and prevalent sin than ontological incompatibility between the research problem being addressed and the theoretical (re) construction being presented. Personally (as most readers will discern), I find myself increasingly drawn to the work of Pierre Bourdieu. Not because I seriously believe that I will extend and develop his oeuvre, but that he gives me a set of tools to explore what accounting is and how it works. In addition, Bourdieu embraces both the power of individual choice (or agency) and recognises the reality and influence of structure arrangements. My advice to PhDs students is to stick to one theoretical approach if they can. While I can charitably accept a paper or thesis where the authors draw on two or more theoreticals to help more clearly address the underlying accounting problem, the path of theoretical pluralism has the extra requirements that the author must clearly explain why they have used more than one theory and how their theories work together to (re)construct 
their research problem. The use of multiple theoretical approaches for their own sake confuse and annoy me.

\section{CONCLUSION}

In conclusion, I repent from my off-handed closing line about promiscuity while defending the descriptive position I adopted in Jacobs (2012) and not abandoning my desire to be provocative. The concerns about ontological incompatibility highlighted by Modell (2013) and Young and Preston (1996) are fair and valid. However, a focus on eclecticism verses purity can miss the point. The central issue is whether a theory is actually 'theorising' our research question. Perhaps if we are more successful in addressing the link between our theory and our accounting problems we will impact accounting practice in the ways advocated by Humphrey and Scapens (1996) and enhance the craft of research in the form argued by Young and Preston (1996). While I am not convinced that the critical realism advocated by Modell (2013) is the solution to the problems presented, I am more than happy to join with him in a call for greater reflexitivity and care in the conduct and presentation of accounting research papers. Therefore, I will abandon my argument for promiscuity and argue instead for monogamy. However, this should be understood as serial monogamy because researchers should be willing to change our theoretical approaches, when necessary, if we wish to make a significant contribution to accounting knowledge and practice.

\section{NOTE}

1 See Chua and Mahama (2011, p. 80) for an excellent discussion of this issue and a careful distinction between theory and theorisation. They define theorisation as drawing on an informing theory to make sense of an empirical research problem or question and to draw relationships between the research problem, the research context and the underlying data.

\section{REFERENCES}

Booth, W. et al. (2008), The Craft of Research, ( $3^{\text {rd }}$ ed., The University of Chicago Press Chicago).

Bourdieu, P. and L. Wacquant (1992), An Invitation to Reflexive Sociology (The University of Chicago Press, Chicago).

- et al. (1991), The Craft of Sociology: Epistemological Preliminaries (de Gruytere, Berlin).

Chua, W.F. and H. Mahama (2011), 'On Theory as a 'Deliverable' and its Relevance in Policy Arenas', Critical Perspectives on Accounting, Vol. 23, No. 1, pp. 78-82.

Humphrey, C. and R. Scapens (1996), 'Theories and Case Studies of Organizational Accounting Practices: Limitation or Liberation', Accounting Auditing and Accountability Journal, Vol. 9, No. 4, pp. 86-106.

Jacobs, K. (2012), 'Making Sense of Social Practice: Theorising Pluralism in Public Sector Accounting Research', Financial Accountability \& Management, Vol. 28, No. 1, pp. 1-25.

Modell, S. (2013), 'Making Sense of Social Practice: Theoretical Pluralism in Public Sector Accounting Research: A Comment', Financial Accountability \& Management, Vol. 29, No. 1, pp. 99-110.

Vaivio, J. (2008), 'Qualitative Management Accounting Research: Rationale, Pitfalls and Potential', Qualitative Research in Accounting and Management, Vol. 5, No. 1, pp. 64-86.

Young, J. and A. Preston (1996), 'Are Accounting Researchers Under the Tyranny of Single Theory Perspectives?', Accounting Auditing and Accountability Journal, Vol. 9, No. 4, pp. 107-11. 